\title{
Optimalisasi Tata Letak Fasilitas Pada Proyek Pembangunan Gedung Sudirman Suite Jakarta Menggunakan Metode Multi Objectives Function
}

\author{
Enriko Siahaan $^{1}$, Sugiyarto $^{2}$, Sunarmasto $^{3}$
}

\author{
1) Mahasiswa Program Studi Teknik Sipil, Fakultas Teknik, Universitas Sebeleas Maret \\ 23)Staff Pengajar Program Studi Teknik Sipil, Fakultas Teknik, Universitas Sebelas Maret \\ Jalan Ir. Sutami No.36A Surakarta 57126.Telp.0271647069, Email: enrikosiahaan93@gmail.com,
}

\begin{abstract}
Purpose of site layout facility is to develop an efficient and effective area system, by way of bring some facility with high intensity of labour being closer. Point of bring these facilities being closer are loss of man-hour because of traveling distance could decrease. Used method on this research is Multi Objectives Function, that is anlyzing of more than one objective function. On this research are traveling distance and safety index. The result of traveling distance analyzing indicate that minimum value of traveling distance occured on scenario 2, with exact value 11168,1383 m, or has been decreased $27 \%$ compared tovalue of traveling distance on existing layout. Site layout facility movement on this reseach indicate that value of safety index has not decreasing significantly from existing layout, so the conclusion scenario 2 was optimal condition suggested on this research
\end{abstract}

Keywords : Optimize, Site Layout, Facility, Multi Objectives Function, Traveling Distance, Safety Index

\begin{abstract}
ABSTRAK
Tujuan dari tata letak fasilitas adalah mengembangkan sebuah sistem area yang efisien dan efektif dengan cara mendekatkan fasilitas-fasilitas yang dilalui pekerja. Pendekatan antar fasilitas yang dilalui pekerja ini agar kehilangan jam kerja karna jarak perjalanan dapat dikurangi. Metode yang digunakan ialah Multi Objectives Function, yaitu analisis terhadap lebih dari satu fungsi objektif, pada hal ini adalah traveling distance dan safety index. Perhitungan traveling distance yang telah dilakukan menunjukkan bahwa nilai minimum TD terjadi pada skenario 2 dengan nilai sebesar 11168,1383 m, atau mengalami penurunan sebesar $27 \%$ dari kondisi awal. Perubahan dari tata letak fasilitas pada penelitian ini tidak menunjukkan penurunan nilai safety index secara signifikan, dengan ini disimpulkan bahwa skenario 2 merupakan saran dari peneliti sebagai kondisi optimal pada penelitian ini.
\end{abstract}

Kata Kunci : Optimalisasi, Tata Letak, Fasilitas, Multi Objectives Function, Traveling Distance, Safety Index

\section{PENDAHULUAN}

Dalam perkembangannya beberapa tahun terakhir, sektor konstruksi mengalami persaingan yang ketat (BPS,2014).Hal tersebut secara tidak langsung tentu saja memacu adanya kompetisi, sehingga untuk mampu bertahan dalam kompetisi sektor konstruksi ini, pelaku usaha harus mampu menemukan cara mengoptimalkan produktivitas dan efisiensi dalam setiap kegiatannya.

Kenyataannya di lapangan, peningkatan produktivitas dan efisiensi secara tepat masih cukup sulit untuk dilakukan. Salah satu kendalanya ialah pihak manajemen sulit menemukan sumber-sumber masalah dan hambatan dengan cepat, karna terbatasnya kemampuan sumber daya manusia serta belum tersedianya alat bantu yang mampu memberi solusi optimal. Faktor yang sebenarnya memiliki potensi untuk dioptimalkan dan sangat memungkinkan untuk dilakukan ialah perubahan tata letak fasilitas, karna hal tersebut sangat berpengaruh langsung pada kinerja pekerja untuk meningkatkan produktivitas dan efisien dalam aktivitas konstruksi. Hal lain yang menyangkut tata letak yang tidak efisien juga akan menyebabkan bertambahnya penanganan material dan biaya penempatan ulang dari barang lainnya serta kerugian secara waktu karna jarak perjalanan yang panjang.

Optimalisasi tata letak ialah suatu usaha dalam perencanaan fasilitas yang bertujuan untuk mengembangkan suatu sistem area yang efisien dan efektif agar tercapai proses yang paling optimal. Perencanaan tata letak memiliki fungsi untuk menentukan dan menempatkan fasilitas-fasilitas penunjang pelaksanaan proyek seperti direksi keet, barak pekerja, genset, tower crane dan sebagainya pada lokasi yang tepat. Tata letak fasilitas sementara tersebut memiliki dampak penting bagi proses 
pengerjaan proyek yang mencakup waktu pekerjaan dan biaya proyek. Setiap proyek tentunya memiliki luas lahan yang berbeda-beda serta memerlukan fasilitas yang berbeda pula dalam pelaksanaan proyek.

Perencanaan tata letak fasilitas ini mempertimbangkan jarak tempuh yang dilalui oleh pekerja, yaitu jarak kumulatif perjalanan pekerja di dalam proyek setiap harinya, dan pengukuran tingkat bahaya (safety index) berupa ukuran tingkat bahaya dari keberadaan fasilitas proyek. Tingkat bahaya dijadikan pertimbangan dengan alasan meminimalisir kecelakaan kerja dikarenakan fasilitas proyek, berhubungan dengan biaya apabila terjadi kecelakaan kerja serta kenyamanan pekerja, agar pekerja tidak mengambil jalan memutar apabila harus melewati fasilitas yang dianggap membahayakan oleh pekerja.

\section{LANDASAN TEORI}

Optimalisasi dapat diartikan sebagai proses atau usaha pencapaian paling menguntungkan. Pada hal ini, untuk perencanaan tata letak (site layout) ialah tahapan dalam perencanaan fasilitas yang bertujuan untuk mengembangkan suatu sistem area yang paling efisien dan efektif. Akan dikatakan efisien apabila penempatan bangunan-bangunan fasilitas dan sarana pada proyek menyesuaikan dan mendukung pergerakan dari para pekerja, sehingga diperoleh efisiensi kerja. Efisiensi kerja pada penelitian ini diartikan sebagai pencapaian perbandingan antara sumber tenaga atau daya dengan hasil pelaksanaan. Karena hal tersebut, letak bangunan-bangunan fasilitas tidak mengganggu antara satu dengan yang lainnya, baik secara jarak maupun ukurannya, agar lalu lintas perjalanan pekerja lancar serta menunjang pekerjaan-pekerjaan pada konstruksi berjalan secara efektif. Efektif yang dimaksud ialah dapat terselesaikannya suatu pekerjaan sesuai dengan rencana (schedule) kerja yang telah disusun.

Perencanaan site layout dibagi menjadi dua, yaitu equal site layout dan unequal site layout. Equal site layout adalah kondisi di mana jumlah lokasi yang tersedia pada area proyek sama dengan jumlah lokasi yang dibutuhkan untuk penempatan fasilitas proyek yang ada, sedangkan unequal site layout merupakan kondisi dimana jumlah lokasi yang tersedia lebih banyak daripada jumlah lokasi yang dibutuhkan untuk penempatan fasilitas yang ada di proyek, sehingga untuk menyeimbangkan antara jumlah fasilitas proyek dengan jumlah lokasi yang tersedia diperlukan adanya dummy.

\section{Jenis Fasilitas}

Tabel 1. Jenis - Jenis Fasilitas

\begin{tabular}{ll}
\hline Jenis & Deskripsi \\
\hline $\begin{array}{l}\text { Temporary Facility } \\
\text { (FasilitasSementara) }\end{array}$ & Fasilitas yang dapat diletakkan diberbagairuang kosongdalamproyek \\
Fixed Facility & Fasilitasyangtidakdapatdipindah- pindah lagi atau memiliki tempat \\
(FasilitasTetap) & yangtetap dalamproyek \\
Obstacle & Area yang tidak dialokasikan di dalamproyek \\
\hline
\end{tabular}

\section{Jarak Tempuh (Traveling Distance)}

Jarak tempuh adalah jarak total atau kumulatif yang ditempuh oleh pekerja dari suatu fasilitas ke fasilitas lain dalam sebuah aktivitas proyek konstruksi. Dirumuskan sebagai berikut :

$$
\text { TravellingDistance }(T D)=\sum_{m, i=1}^{n} d_{m i} \times f_{m i}
$$

Dengan $: \mathrm{n} \quad=$ Jumlah fasilitas dalam proyek

$\mathrm{f}_{\mathrm{mi}} \quad=$ frekuensi perjalanan dari fasilitas ' $\mathrm{m}$ ' menuju fasilitas ' $\mathrm{i}$ '

$\mathrm{d}_{\mathrm{mi}} \quad=$ Jarak dari fasilitas ' $\mathrm{m}$ ' menuju fasilitas ' $i$ '

TingkatKeamanandanKeselamatan(SafetyIndex)

Safety Index dirumuskan sebagai berikut : 


$$
\text { Safety Index }(S I)=\sum_{m, i=1}^{n} S_{m i} \times f_{m i}
$$

Dengan : $\mathrm{n}=$ Jumlah fasilitas total pada proyek

$\mathrm{S}_{\mathrm{mi}}=$ Tingkat keamanan dan keselamatan antar fasilitas ' $\mathrm{m}$ ' dan ' $\mathrm{i}$ '

$\mathrm{F}_{\mathrm{mi}}=$ Frekuensi perjalanan antar fasilitas ' $\mathrm{m}$ ' dan ' $\mathrm{i}$ '

\section{METODE PENELITIAN}

\section{Survei Lokasi Proyek dan Identifikasi Fasilitas}

Tahap ini adalah tahap pengumpulan data awal berupa nama proyek, detail proyek, letak proyek, serta site layout proyek. Data yang ada ditijau untuk direncanakan skenarionya. Di lapangan terdapat dua jenis fasilitas, yaitu fasilitas tetap yang tidak dapat dipindah, dan fasilitas sementara yang akan direncanakan skenrionya.

\section{Pengukuran Jarak Antar Fasilitas}

Pengukuran menggunakan satuan meter dan didasarkan pada jarak yang paling memungkinkan di proyek. Untuk kriteria nilai safety index didasarkan pada proporsi yang dilewati.

\section{Menghitung Frekuensi Perjalanan Pekerja}

Penghitungan dilakukan menggunakan metode wawancara dengan manajer proyek selaku expert. Nilai frekuensi antar fasilitas dengan sebaliknya memiliki nilai yang sama.

\section{Pemodelan Tata Letak Fasilitas}

Tahap ini ialah penyusunan skenario secara tertulis dengan rinciannya serta pertimbangan dipindahkannya fasilitas demi tujuan mendapatkan tata letak yang paling optimal.

\section{Analisis Optimalisasi Multi Objective Function}

Data hasil penghitungan traveling distancedan safety index kemudian disajikan untuk dilakukan optimalisasi berdasarkan jarak tempuh paling minimum.Kemudian data dari hasil penghitungan safety index disajikan untuk dilakukan optimalisasi berdasarkan tingkat keselamatan dan keamanan yang paling minimum. Langkah berikutnya adalah menggabungkan hasil penghitungan traveling distance minimum dan safety index minimum untuk mendapatkan sebuah grafik hubungan antara keduanya sehingga dapat terbaca dengan diagram pareto optima, untuk kemudian diambil keputusan skenario site layout yang paling optimal diproyek tersebut. Diagram pareto optima ialah suatu gambar yang mengurutkan klasifikasi data dari kiri ke kanan menurut ranting tertinggi hingga terendah, digunakan untuk mencari sebuah nilai optimal dari hubungan dua jenis data,dalam penelitian ini digunakan untuk melihat travelling distance (jarak tempuh) dan safety index kemudian melihat perbandingannya dan menentukan salah satu untuk dijadikan prioritas sehingga dapat menentukan skenario yang paling optimal. Dikatakan optimal, apabila nilai dari travelling distance atau safety index mengalami penurunan.

Dengan demikian maka fungsi objektif yang paling optimal memiliki kriteria antara travelling distance (jarak tempuh) terkecil dan nilai safety index yang terkecil. Kurva diagram pareto optima akan menunjukkan titik-titik tersebut yang memiliki kemungkinan site layout optimal 


\section{ANALISIS DAN PEMBAHASAN}

Setelah mengikuti langkah - langkah yang telah dijelaskan di metode, selanjutnya data - data direncanakan dalam beberapa skenario.

Tabel 2.Skenario 0 (Kondisi Awal Proyek)

\begin{tabular}{cccccc}
\hline Lokasi & A & B & C & D & E \\
Fasilitas & Gudang 1 & Dummy 1 & $\begin{array}{c}\text { Bekisting Core } \\
\text { Wall }\end{array}$ & $\begin{array}{c}\text { Pabrikasi } \\
\text { Besi }\end{array}$ & $\begin{array}{c}\text { Precast } \\
\text { Dinding } \\
\text { Kolom }\end{array}$ \\
\hline Lokasi & F & G & H & I & J \\
\hline Fasilitas & $\begin{array}{c}\text { Bekisting Plat } \\
\text { Balok 2 }\end{array}$ & $\begin{array}{c}\text { Bekisting } \\
\text { Plat Balok 1 }\end{array}$ & Gudang 2 & $\begin{array}{c}\text { Gudang } \\
3\end{array}$ & Subcon Office \\
\hline Lokasi & K & L & M & N & O \\
\hline Fasilitas & Barak Pekerja 2 & Gudang 4 & Stockyard Besi & $\begin{array}{c}\text { Barak } \\
\text { Pekerja 1 }\end{array}$ & Toilet Pekerja \\
\hline
\end{tabular}

Tabel 3.Skenario 1

\begin{tabular}{cccccc}
\hline Lokasi & A & B & C & D & E \\
\hline Fasilitas & Gudang 1 & Dummy 1 & Stockyard Besi & $\begin{array}{c}\text { Pabrikasi } \\
\text { Besi }\end{array}$ & $\begin{array}{c}\text { Precast Dinding } \\
\text { Kolom }\end{array}$ \\
\hline Lokasi & $\mathrm{F}$ & $\mathrm{G}$ & $\mathrm{H}$ & $\mathrm{I}$ & $\mathrm{J}$ \\
\hline Fasilitas & $\begin{array}{c}\text { Bekisting Plat } \\
\text { Balok 2 }\end{array}$ & Gudang 2 & $\begin{array}{c}\text { Bekisting Plat } \\
\text { Balok 1 }\end{array}$ & $\begin{array}{c}\text { Gudang } \\
3\end{array}$ & Subcon Office \\
\hline Lokasi & $\mathrm{K}$ & $\mathrm{L}$ & $\mathrm{M}$ & $\mathrm{N}$ & $\mathrm{O}$ \\
\hline Fasilitas & Barak Pekerja 2 & Gudang 4 & $\begin{array}{c}\text { Bekisting Core } \\
\text { Wall }\end{array}$ & $\begin{array}{c}\text { Barak } \\
\text { Pekerja } \\
1\end{array}$ & Toilet Pekerja \\
\hline
\end{tabular}

Tabel 4.Skenario 2

\begin{tabular}{cccccc}
\hline Lokasi & $\mathrm{A}$ & $\mathrm{B}$ & $\mathrm{C}$ & $\mathrm{D}$ & $\mathrm{E}$ \\
\hline Fasilitas & Dummy 1 & Gudang 1 & Stockyard Besi & $\begin{array}{c}\text { Pabrikasi } \\
\text { Besi }\end{array}$ & $\begin{array}{c}\text { Precast } \\
\text { Dinding Kolom }\end{array}$ \\
\hline Lokasi & $\mathrm{F}$ & $\mathrm{G}$ & $\mathrm{H}$ & $\mathrm{I}$ & $\mathrm{J}$ \\
\hline Fasilitas & $\begin{array}{c}\text { Bekisting Plat } \\
\text { Balok 2 }\end{array}$ & Gudang 2 & $\begin{array}{c}\text { Bekisting Plat } \\
\text { Balok 1 }\end{array}$ & Gudang 3 & Subcon Office \\
\hline Lokasi & $\mathrm{K}$ & $\mathrm{L}$ & $\mathrm{M}$ & $\mathrm{N}$ & $\mathrm{O}$ \\
\hline Fasilitas & $\begin{array}{c}\text { Barak Pekerja } \\
\text { 2 }\end{array}$ & Gudang 4 & $\begin{array}{c}\text { Bekisting Core } \\
\text { Wall }\end{array}$ & $\begin{array}{c}\text { Barak } \\
\text { Pekerja 1 }\end{array}$ & Toilet Pekerja \\
\hline
\end{tabular}


Tabel 5. Skenario 3

\begin{tabular}{cccccc}
\hline Lokasi & A & B & C & D & E \\
\hline Fasilitas & $\begin{array}{c}\text { Toilet } \\
\text { Pekerja }\end{array}$ & Gudang 1 & Stockyard Besi & $\begin{array}{c}\text { Pabrikasi } \\
\text { Besi }\end{array}$ & $\begin{array}{c}\text { Precast Dinding } \\
\text { Kolom }\end{array}$ \\
\hline Lokasi & $\mathrm{F}$ & $\mathrm{G}$ & $\mathrm{H}$ & $\mathrm{I}$ & $\mathrm{J}$ \\
\hline Fasilitas & $\begin{array}{c}\text { Bekisting Plat } \\
\text { Balok 2 }\end{array}$ & Gudang 2 & $\begin{array}{c}\text { Bekisting Plat } \\
\text { Balok 1 }\end{array}$ & Gudang 4 & Subcon Office \\
\hline Lokasi & $\mathrm{K}$ & $\mathrm{L}$ & $\mathrm{M}$ & $\mathrm{N}$ & $\mathrm{O}$ \\
\hline Fasilitas & Barak Pekerja & Gudang 3 & $\begin{array}{c}\text { Bekisting Core } \\
\text { Wall }\end{array}$ & $\begin{array}{c}\text { Barak } \\
\text { Pekerja 1 }\end{array}$ & Dummy 1 \\
\hline
\end{tabular}

Tabel 6.Skenario 4

\begin{tabular}{cccccc}
\hline Lokasi & A & B & C & D & E \\
\hline Fasilitas & Gudang 1 & Dummy 1 & $\begin{array}{c}\text { Bekisting } \\
\text { Core Wall }\end{array}$ & $\begin{array}{c}\text { Pabrikasi } \\
\text { Besi }\end{array}$ & $\begin{array}{c}\text { Precast } \\
\text { Dinding } \\
\text { Kolom }\end{array}$ \\
\hline Lokasi & $\mathrm{F}$ & $\mathrm{G}$ & $\mathrm{H}$ & $\mathrm{I}$ & $\mathrm{J}$ \\
\hline Fasilitas & $\begin{array}{c}\text { Bekisting Plat } \\
\text { Balok 2 }\end{array}$ & $\begin{array}{c}\text { Bekisting Plat } \\
\text { Balok 1 }\end{array}$ & Gudang 2 & Gudang 3 & Subcon Office \\
\hline Lokasi & $\mathrm{K}$ & $\mathrm{L}$ & $\mathrm{M}$ & $\mathrm{N}$ & $\mathrm{O}$ \\
\hline Fasilitas & $\begin{array}{c}\text { Barak Pekerja } \\
\text { 2 }\end{array}$ & Gudang 4 & $\begin{array}{c}\text { Stockyard } \\
\text { Besi }\end{array}$ & $\begin{array}{c}\text { Barak } \\
\text { Pekerja 1 }\end{array}$ & Toilet Pekerja \\
\hline
\end{tabular}

Tabel 7.Skenario 5

\begin{tabular}{cccccc}
\hline Lokasi & A & B & C & D & E \\
\hline Fasilitas & Gudang 1 & Dummy 1 & $\begin{array}{c}\text { Bekisting } \\
\text { Core Wall }\end{array}$ & $\begin{array}{c}\text { Pabrikasi } \\
\text { Besi }\end{array}$ & $\begin{array}{c}\text { Precast Dinding } \\
\text { Kolom }\end{array}$ \\
\hline Lokasi & $\mathrm{F}$ & $\mathrm{G}$ & $\mathrm{H}$ & $\mathrm{I}$ & $\mathrm{J}$ \\
\hline Fasilitas & $\begin{array}{c}\text { Bekisting Plat } \\
\text { Balok 2 }\end{array}$ & $\begin{array}{c}\text { Bekisting Plat } \\
\text { Balok 1 }\end{array}$ & Gudang 2 & Gudang 3 & Subcon Office \\
\hline Lokasi & $\mathrm{K}$ & $\mathrm{L}$ & $\mathrm{M}$ & $\mathrm{N}$ & $\mathrm{O}$ \\
\hline Fasilitas & Barak Pekerja & Gudang 4 & $\begin{array}{c}\text { Stockyard } \\
\text { Besi }\end{array}$ & $\begin{array}{c}\text { Barak } \\
\text { Pekerja 1 }\end{array}$ & Toilet Pekerja \\
\hline
\end{tabular}

Tabel 8. Skenario 6

\begin{tabular}{cccccc}
\hline Lokasi & A & B & C & D & E \\
\hline Fasilitas & Gudang 1 & Dummy 1 & Bekisting & Pabrikasi & Precast Dinding \\
\hline
\end{tabular}




\begin{tabular}{cccccc}
\hline & & & Core Wall & Besi & Kolom \\
\hline Lokasi & $\mathrm{F}$ & $\mathrm{G}$ & $\mathrm{H}$ & $\mathrm{I}$ & $\mathrm{J}$ \\
\hline Fasilitas & $\begin{array}{c}\text { Bekisting Plat } \\
\text { Balok 2 }\end{array}$ & $\begin{array}{c}\text { Bekisting Plat } \\
\text { Balok 1 }\end{array}$ & Gudang 2 & Gudang 3 & Subcon Office \\
\hline Lokasi & $\mathrm{K}$ & $\mathrm{L}$ & $\mathrm{M}$ & $\mathrm{N}$ & $\mathrm{O}$ \\
\hline Fasilitas & $\begin{array}{c}\text { Barak Pekerja } \\
\text { 2 }\end{array}$ & Gudang 4 & $\begin{array}{c}\text { Stockyard } \\
\text { Besi }\end{array}$ & $\begin{array}{c}\text { Barak } \\
\text { Pekerja 1 }\end{array}$ & Toilet Pekerja \\
\hline
\end{tabular}

Tabel 9. Rekapitulasi penghitungan nilai TD dan SI

\begin{tabular}{lcc}
\hline Skenario & $\begin{array}{c}\text { Traveling } \\
\text { Distance }\end{array}$ & Safety Index \\
\hline Skenario 0 & 15336.3037 & 431.4807539 \\
Skenario 1 & 11697.3384 & 444.5836517 \\
Skenario 2 & 11168.1383 & 446.0731248 \\
Skenario 3 & 12614.4206 & 517.5645593 \\
Skenario 4 & 13977.2962 & 422.7897975 \\
Skenario 5 & 14804.1564 & 415.9465913 \\
Skenario 6 & 14548.9392 & 419.6045934 \\
\hline
\end{tabular}

\section{KESIMPULAN}

1. Nilai Traveling Distance yang paling kecil diperoleh pada skenario 2 dengan persentase besar penurunan $27 \%$ dari kondisi awal

2. Nilai Safety Index paling kecil diperoleh dari skenario 5 dengan persentase besar penurunan $4 \%$ dari kondisi awal

3. Perubahan dari tata letak fasilitas pada penelitian ini tidak menunjukkan penurunan nilai safety index secara signifikan, dengan ini disimpulkan bahwa skenario 2 merupakan saran dari peneliti sebagai kondisi optimal pada penelitian ini.

\section{SARAN}

1. Dalam penghitungan optimalisasi tata letak fasilitas dapat menggunaakan metode lainnya seperti metode koloni semut.

2. Memperbanyak skenario pada pemodelan site layout untuk memperoleh hasil yang lebih variatif.

3. Melakukan perbandingan dengan beberapa teori lainnya seperti teori ARC atau program komputer yang berhubungan dengan pemindahan tata letak fasilitas seperti ALDEP, Corelap atau WinQSB.

\section{Daftar Pustaka}

Effendi, D.T., Adi, T.J.W.,\&Putri, Y.E., (2012).Optimasi (Unequal) Site Layout Menggunakan Multi Objective Function pada Proyek Pembangunan Apartemen Puncak Kertajaya Surabaya. JournalofTeknik POMITS, Vol. 1,p. 1-6

Gunawan, R.O.,\&Nurcahyo, C.B., (2014).Optimasi Tata Letak Fasilitas Menggunakan Multi Objective Function pada Proyek Apartemen Nine Residence Jakarta. JournalofTeknik POMITS, Vol. 3,(2) p. 
Hegazy, T.,\&Elbeltagi,E. (1999).Evosite: AnEvolution Based Model forSite LayoutPlanning. ASCEJournal of Computing in CivilEngineering, 13,(1)p.198-206. Gunawan, R.O.,\&Nurcahyo, C.B., (2014),Optimasi Tata Letak Fasilitas Menggunakan Multi Objective Function pada Proyek Apartemen Nine Residence Jakarta. JournalofTeknik POMITS, Vol. 3,(2) p.

Pranarka,D\&Adi, T.W.(2012).SiteLayoutUsingMulti-ObjectiveFunctionOn ProjectA.JournalofTeknik POMITS,Vol.1.(1), p.1-6

Tommelein,I.D.,Levitt,R.E.,\&HayesR.B.(1992).Sight PlanModelfor Site Layout. ASCE Journalof ConstructionEngineeringandManagement,118(4), p.749-766, Gunawan, R.O.,\&Nurcahyo, C.B., (2014).Optimasi Tata Letak Fasilitas Menggunakan Multi Objective Function pada Proyek Apartemen Nine Residence Jakarta. JournalofTeknik POMITS, Vol. 3,(2) p.

Yeh,I.C.(1995).Construction-SiteLayoutUsing Annelaed NeuralNetwork.JournalofComputing in Civil Engineering,9(3) p.201-208, Gunawan, R.O.,\&Nurcahyo, C.B., (2014).Optimasi Tata Letak Fasilitas Menggunakan Multi Objective Function pada Proyek Apartemen Nine Residence Jakarta. JournalofTeknik POMITS, Vol. 3,(2) p.

Sidharno,W\& Toriq, A.G.(2010).Analisa Tata Letak Fasilitas dan Aliran Bahan pada Proyek Konstruksi. Skripsi Jurusan Teknik Sipil dan Lingkungan FT Universitas Gadjah Mada 